\title{
ИСКУССТВЕННЫЙ ИНТЕЛЛЕКТ В МЕТОДИКЕ ПРЕПОДАВАНИЯ ИНОСТРАННЫХ ЯЗЫКОВ
}

\section{ARTIFICIAL INTELLIGENCE IN FOREIGN LANGUAGE TEACHING METHODS}

\section{Petrova}

Summary: Artificial intelligence technology allows students to acquire and practice the necessary professional skills of the 21st century. The author of the article offers an innovative solution to achieve a new level of interactivity in postgraduate studies - the adoption of the chatbots in FLT. As a result of an in-depth analysis of computer language programs, the advantages and disadvantages of chatbots were identified, and the author's model of virtual assistants for Ph.D. students was developed. Chatbots Professor_EDU and MG_Bot act as a high-tech addition to the Academic English course, providing adaptive and personalized training and task verification in real-time mode.

Keywords: Academic English, Artificial Intelligence, foreign language teaching methods (FLT methods), chatbot, post-graduate studies.

\author{
Петрова Марина Георгиевна \\ Российский университет дружбы народов \\ petrmar2005@mail.ru
}

Аннотация: Технология искусственного интеллекта дает сегодня студентам возможность приобрести и практиковать основные профессиональные навыки 21-го века. Автор статьи предлагает инновационное решение для достижения нового уровня интерактивности обучения в аспирантуре - внедрение чат-ботов по академическому английскому. В результате глубокого анализа компьютерных языковых программ выявлены преимущества и недостатки чат-ботов и разработана авторская модель виртуальных помощников для аспирантов. Чат-боты Professor_EDU и MG_Bot выступают высокотехничным дополнением к курсу «Academic English», обеспечивая адаптивное и персонализированное обучение и проверку заданий в режиме реального времени.

Ключевые слова: искусственный интеллект, методика преподавания иностранных языков, чат-бот, академический английский, аспирантура.

менте eLearning, чат-боты представляются многообещающим инструментом, поскольку могут сопровождать каждого слушателя индивидуально, в соответствии с его уровнем и выбранным темпом освоения материала, делая обучение доступным практически для любого человека, имеющего доступ к Wi-Fi [2]. С чат-ботом, программой, имитирующей человеческую речь, студенты могут общаться на иностранном языке каждый день в любое удобное для них время, не переживая о том, что кто-то сделает им замечание из-за совершенной ошибки. Более того, чат-бот предложит несколько вариантов для улучшения результата.

Чат-боты прошли довольно долгий исторический путь с 1966 года, когда Джозеф Вейценбаум, профессор Массачусетского технологического института, создал Элизу, первого виртуального собеседника. За полвека чат-боты усовершенствовались до такого уровня, что их стали использовать в изучении иностранных языков. В таблице №1 представлены лучшие модели виртуальных помощников для улучшения навыков письма в иностранном языке.

Настало время внедрить искусственный интеллект в обучение иностранным языкам и проложить путь к персонализированному образованию. Институт иностранных языков (РУДН) начал использовать возможности нейронных сетей и искусственного интеллекта в обучении аспирантов. 
Преимущества и недостатки образовательных чат-ботов

\begin{tabular}{|c|c|c|c|c|}
\hline № & Имя чат-бота & Описание чат-бота & Преимущества & Недостатки \\
\hline 1. & A.L.I.C.E & $\begin{array}{c}\text { Один из самых старых чат- } \\
\text { ботов, который специально } \\
\text { разрабатывался в качестве } \\
\text { помощника изучающим } \\
\text { английский язык }\end{array}$ & $\begin{array}{l}\text {-возможность выбрать различных персо- } \\
\text { нажей, } \\
\text {-довольно быстрые ответы, } \\
\text { - юмор, } \\
\text {-обучаемость и уточнения в диалоге }\end{array}$ & $\begin{array}{l}\text {-устаревший интерфейс, } \\
\text {-некоторые персонажи для общения } \\
\text { платные, } \\
\text {-любую не совсем цензурную } \\
\text { лексику бот воспринимает, как } \\
\text { оскорбление, } \\
\text { - нет общения через микрофон }\end{array}$ \\
\hline 2. & Mitsuku & $\begin{array}{c}\text { Довольно приятный чат-бот, с } \\
\text { которым легко общаться }\end{array}$ & $\begin{array}{l}\text {-есть версия с использованием flash и без } \\
\text { него, } \\
\text {-можно включить микрофон, } \\
\text {-логичные диалоги, } \\
\text {-использование уточнений, } \\
\text {-чат-бот понимает сокращения. }\end{array}$ & $\begin{array}{l}\text { - нет общения через микрофон, } \\
\text { - если включить звук и музыку, то } \\
\text { услышать ответы можно только на } \\
\text { японском. }\end{array}$ \\
\hline 3. & Splotchy & $\begin{array}{l}\text { Веселый чат-бот, который } \\
\text { создан с целью именно по- } \\
\text { веселиться }\end{array}$ & $\begin{array}{l}\text { - смешные ответы, } \\
\text {-присутствует сленг, -скорость ответов } \\
\text { высокая }\end{array}$ & $\begin{array}{l}\text {-старый интерфейс, } \\
\text {-заявлена возможность услышать } \\
\text { ответы, но звука от бота нет, } \\
\text {-повторяющиеся ответы, } \\
\text { - нет общения через микрофон }\end{array}$ \\
\hline 4. & Cleverbot & Бот, созданный британцами & $\begin{array}{l}\text {-приятный интерфейс, } \\
\text {-есть свое приложение и возможность } \\
\text { подключить чат себе в мессенджер на } \\
\text { фейсбуке, } \\
\text {-присутствует юмор и реалистичные ответы, } \\
\text {-возможность говорить с ботом через } \\
\text { микрофон }\end{array}$ & $\begin{array}{c}\text {-иногда странные и нелогичные } \\
\text { ответы, которые чатбот подхватил } \\
\text { от пользователей-троллей }\end{array}$ \\
\hline 5. & Existor & $\begin{array}{c}\text { Сайт, который специализиру- } \\
\text { ется на создании ботов и пред- } \\
\text { лагает возможность создать } \\
\text { своего собственного }\end{array}$ & $\begin{array}{l}\text {-удобный и современный интерфейс, } \\
\text {-возможность говорить с ботом через } \\
\text { микрофон, выбирать из нескольких персо- } \\
\text { нажей, } \\
\text {-имитация эмоций персонажа, который } \\
\text { общается с пользователем }\end{array}$ & $\begin{array}{l}\text {-не всегда логичный диалог, } \\
\text {-аватары, когда задумываются, } \\
\text { выглядят пугающе }\end{array}$ \\
\hline 6. & Elbot & $\begin{array}{c}\text { Более современный чат-бот, с } \\
\text { которым довольно интересно } \\
\text { общаться }\end{array}$ & $\begin{array}{l}\text { - простой и достаточно современный } \\
\text { интерфейс, } \\
\text {-веселые ответы и анимация, } \\
\text {-длинные предложения, над которыми } \\
\text { можно поразмышлять, } \\
\text {-логичные диалоги, } \\
\text {-есть приложение для android и ios. }\end{array}$ & $\begin{array}{l}\text {-нет общения через микрофон, } \\
\text {-иногда повторяющиеся ответы }\end{array}$ \\
\hline 7. & iGod & $\begin{array}{c}\text { Бот имитирует общение от } \\
\text { имени Бога }\end{array}$ & $\begin{array}{l}\text {-веселый посыл, } \\
\text {-бот действительно пытается показать себя } \\
\text { божеством, } \\
\text {-ведет достаточно логичные диалоги. }\end{array}$ & $\begin{array}{l}\text {-нет общения через микрофон, } \\
\text {-устаревший и скучный интерфейс, } \\
\text { который работает через flash-player. }\end{array}$ \\
\hline 8. & Mondly & $\begin{array}{c}\text { Программа для обучения язы- } \\
\text { ку, которая имеет две версии } \\
\text { - для браузера и мобильное } \\
\text { приложение }\end{array}$ & $\begin{array}{l}\text {-несколько ответов, } \\
\text {-ответы, озвученные мужским или женским } \\
\text { голосом, помогают научиться правильному } \\
\text { произношению, } \\
\text {-возможность выбрать ответ, сказать свой } \\
\text { собственный или ввести его в диалоговом } \\
\text { окне, } \\
\text {-чат-бот уточняет ответы, } \\
\text {-Американская или Британская версия } \\
\text { английского языка. }\end{array}$ & \\
\hline 9. & Andy & $\begin{array}{c}\text { Приложение, разработанное } \\
\text { специально для разговорной } \\
\text { практики на английском языке. }\end{array}$ & $\begin{array}{l}\text {-легкий разговор с ботом, } \\
\text {-лингвистические игры, } \\
\text {-изучение грамматических правил от “на- } \\
\text { чинающего « до « продвинутого”, } \\
\text {-наращивание лексического ресурса, } \\
\text {-объяснение ошибок и новых слов, } \\
\text {-примеры использования новых лексиче- } \\
\text { ских единиц, } \\
\text {-грамматические тесты. }\end{array}$ & \\
\hline
\end{tabular}


Настало время внедрить искусственный интеллект в обучение иностранным языкам и проложить путь к персонализированному образованию. Институт иностранных языков (РУДН) начал использовать возможности нейронных сетей и искусственного интеллекта в обучении аспирантов.

Искусственный интеллект интегрирован в процесс обучения. Благодаря его использованию можно учесть потребности каждого аспиранта. Поэтому педагоги собирают данные об обучающихся, их способностях, интересах, проектах, проблемах и научных исследованиях.

Специалисты учитывают эти данные при создании чат-ботов.

Ни для кого не секрет, что на третьем этапе высшего образования аспиранты должны публиковать результаты своих исследований в научных журналах, индексируемых в Web of Science или Scopus. Возникает много вопросов:

- Как написать научную статью на академическом английском языке?

- Как выбрать научный журнал в соответствии с вашей стратегией?

- Как написать сопроводительное письмо в научный журнал?

- Где студент может найти словарь с профессиональными терминами?

С целью создания чат-бота по вопросу написания научной статьи было проведено компьютерное вебинтервью, в котором приняли участие 200 респондентов из 4 российских высших учебных заведений: Российского Университета Дружбы Народов, Московского государственного университета имени М. В. Ломоносова, Московского государственного лингвистического университета, Северо-Восточного федерального университета. Опрос показал, что только 14 процентов опрошенных могут писать исследования на академическом английском языке и публиковать их в международных научных журналах.

Таким образом, для мессенджера «Telegram» было решено разработать и внедрить в учебный процесс двух чат-ботов, сопровождающих аспирантов при написании научной статьи на английском языке.

В результате работы экспертной группы, состоящей из 2 разработчиков, 2 преподавателей, 6 аспирантов, чат-бот №1 наделен следующими функциями:

- информирование аспирантов о требованиях к написанию научной статьи на английском языке в рецензируемом высокорейтинговом журнале;

- знакомство с профессиональной терминологией для направлений: «Образование и педагогиче- ские науки», «Языкознание и литературоведение», «Психологические науки»;

- тренировка профессиональных терминов;

- обучение написанию «Сопроводительного письма» в редакцию научного журнала.

Демонстрация прототипа чат-бота, обеспечивает прием обращения от пользователя; интеграцию с существующими биллинговыми системами; обеспечение аспирантов повсеместным доступом к информации - с любого персонального компьютера или мобильного устройства (смартфона), подключенного к сети Интернет, ввод Системы в действие.

Структура чат-бота по имени Professor_EDU (Рисунок 1) включает в себя 5 подсистем: «Сопроводительное письмо», «Глоссарий», «Выбор журнала», «Контроль и тестирование», «Обратная связь (бот поддержки)».

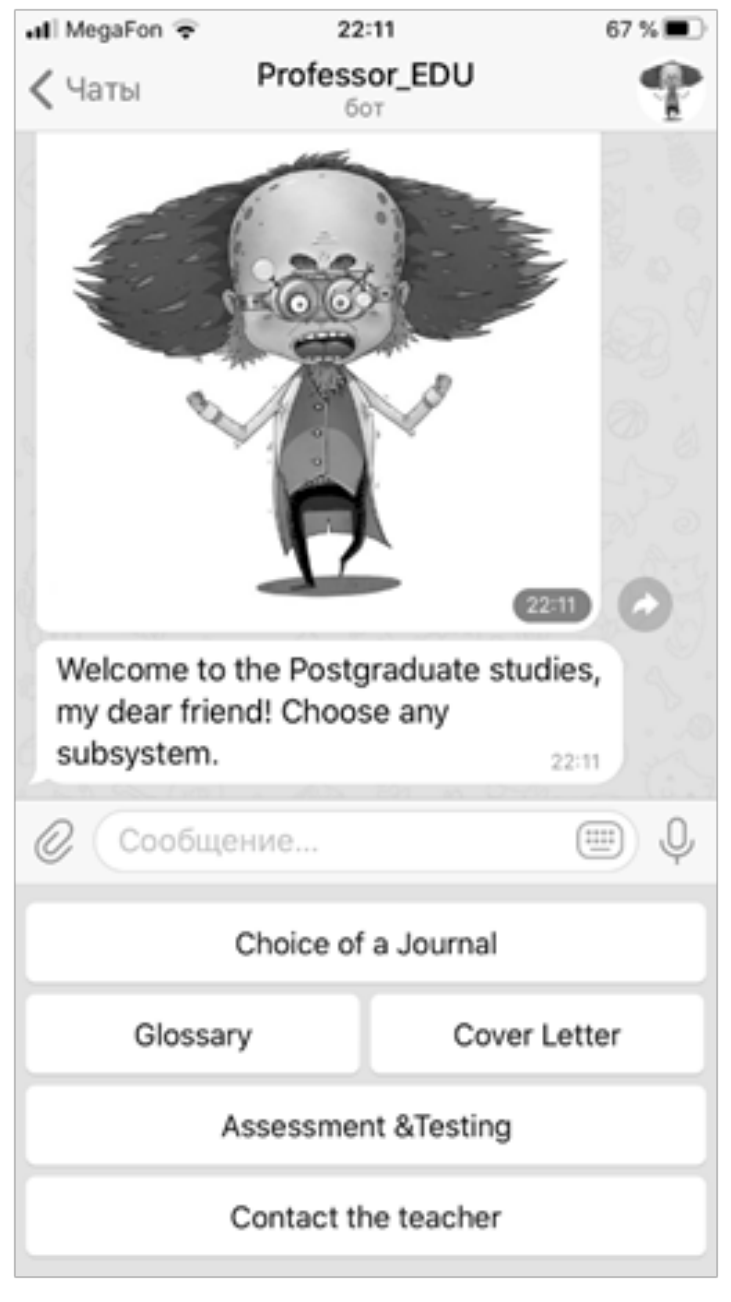

Рис. 1. Чат-бот №1 Professor_EDU

Рисунок 2 демонстрирует работу чат-бота во всех подсистемах. Подсистема «Выбор журнала» обучает аспирантов требованиям научных журналов, включенных в такие наукометрические базы данных, как РИНЦ, BAK, Web of Science и Scopus. 


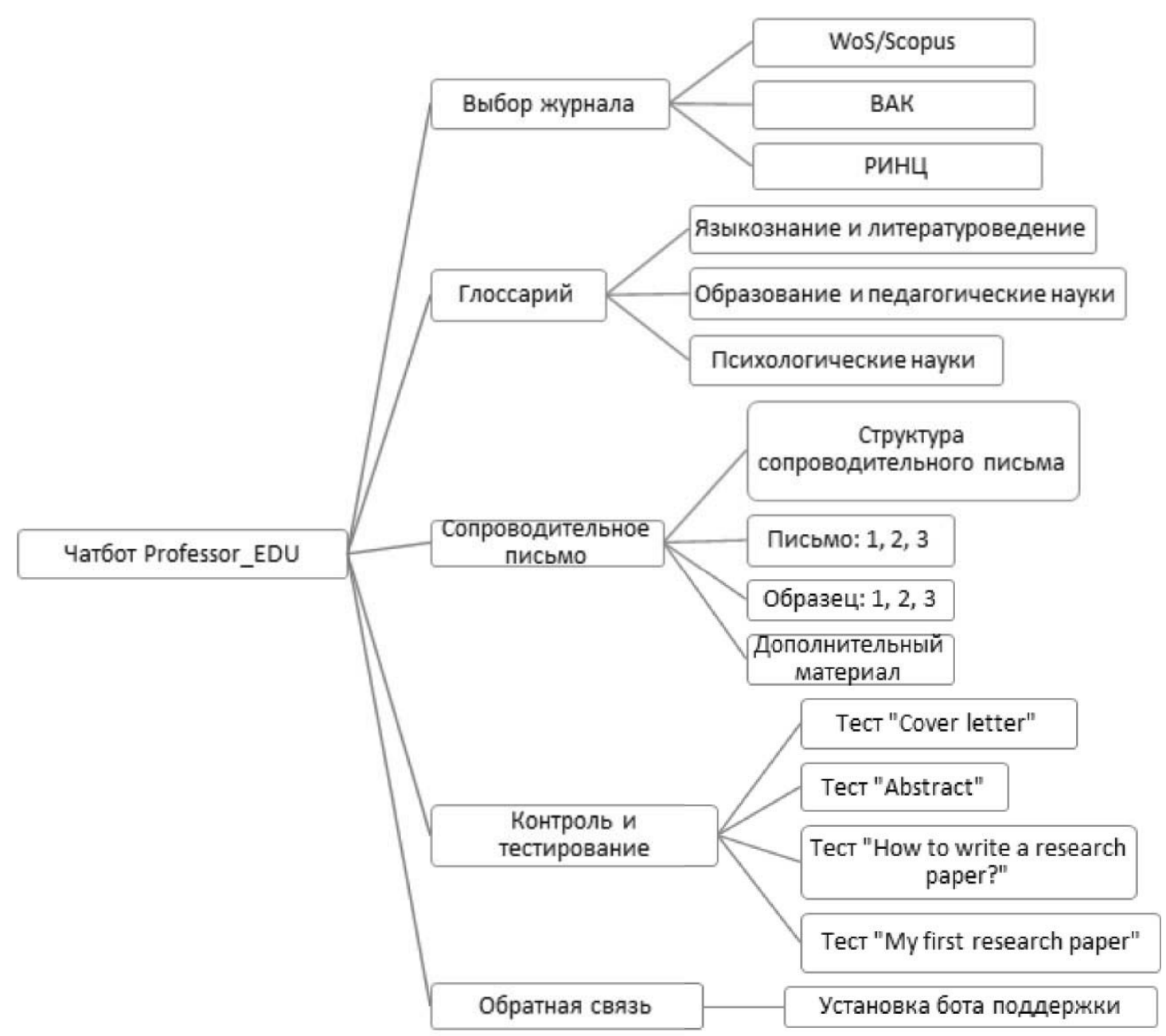

Рис. 2. Струкутра чат-бота Professor_EDU

В подсистеме «Оценка и тестирование» аспиранты отрабатывают свои знания по контрольно-измерительным материалам.

Подсистема «Глоссарий» включает профессиональные термины на английском языке по трем направлениям аспирантуры Института иностранных языков РУДН: «Языкознание и литературоведение», «Образование и педагогические науки» и «Психологические науки». В каждый глоссарий входит более тысячи лексических единиц.

Взаимодействуя с аспирантами, чат-боты могут быстро адаптироваться к специфике академического английского языка. Chatbot Professor_EDU помогает пользователям улучшить грамматику и навыки в написании научной статьи, а также расширить профессиональный словарный запас. Обратную связь предполагает чат-бот службы поддержки MG_Bot (Рисунок 3). Бот №2 решает технические проблемы, сотрудничает с каждым аспирантом 24 часа в сутки.

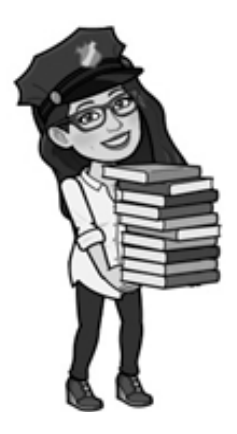

Рис. 3. Чат-бот службы поддержки MG_Bot

Чат-бот - это программа, разрабатываемая под определенную цель на основе технологий машинного обучения и нейросетей.

Для чат-бота № 1 использованы технологии фундаментальной обработки естественного языка. Это - сегментация (разбиение на предложения), лемматизация и 
выделение ключевых слов.

Для бота № 2 экспертная группа использовала технологии машинного обучения, прежде всего глубокие нейронные сети. В результате углубленного анализа существующих чат-ботов и мозговых штурмов экспертная группа преподавателей и аспирантов (20 человек) создала систему классификации намерений с использованием базового НЛП и нейронной сети на основе нормализованной экспоненциальной функции. Интеллектуальные ассистенты помогают аспирантам как в изучении академического английского языка, так и в подготовке к публикации рукописей.
Таким образом, став частью экосистемы обучения иностранным языкам, чат-бот как продукт искусственного интеллекта:

- помогает отслеживать индивидуальный прогресс каждого обучающегося;

- создает «инновационную индивидуальную траекторию преподавателя иностранного языка» [3];

- адаптирует образовательный процесс к индивидуальной скорости обучения студента и предлагает задания возрастающей сложности;

- делает процесс обучения более эффективным;

- повышает вовлеченность через геймификацию [4];

- способствует развитию профессиональных компетенций.

\section{ЛИТЕРАТУРА}

1. Чернышкова H.B. SMART-технологии в преподавании иностранного языка // Филологические науки. Вопросы теории и практики. Тамбов: Грамота, 2018. № 2(80). Ч. 1. С. 211-214.

2. Чат-боты в электронном обучении [Электронный ресурс] URL: https://etu.ru/ru/on-line-obuchenie/dajdzhest-elearning/chat-boty-v-elektronnom-obucheni (дата обращения:15.03.2020).

3. Karsenti Thierry, Kozarenko Olga. Новые технологические тренды и инновационное обучение иностранным языкам: каковы наиболее эффективные стратегии обучения? // XLinguae, издательство Slovenská Vzdelávacia a Obstarávacia s.r.o. (Nitra), том 12, № 1, 2019. C. 128-144.

4. Искусственный интеллект в образовании: семь вариантов применения [Электронный ресурc] URL: https://the-accel.ru/iskusstvennyiy-intellekt-vobrazovanii-sem-variantov-primeneniya/ (дата обращения:15.03.2020).

( П Петрова Марина Георгиевна (petrmar2005@mail.ru).

Журнал «Современная наука: актуальные проблемы теории и практики»

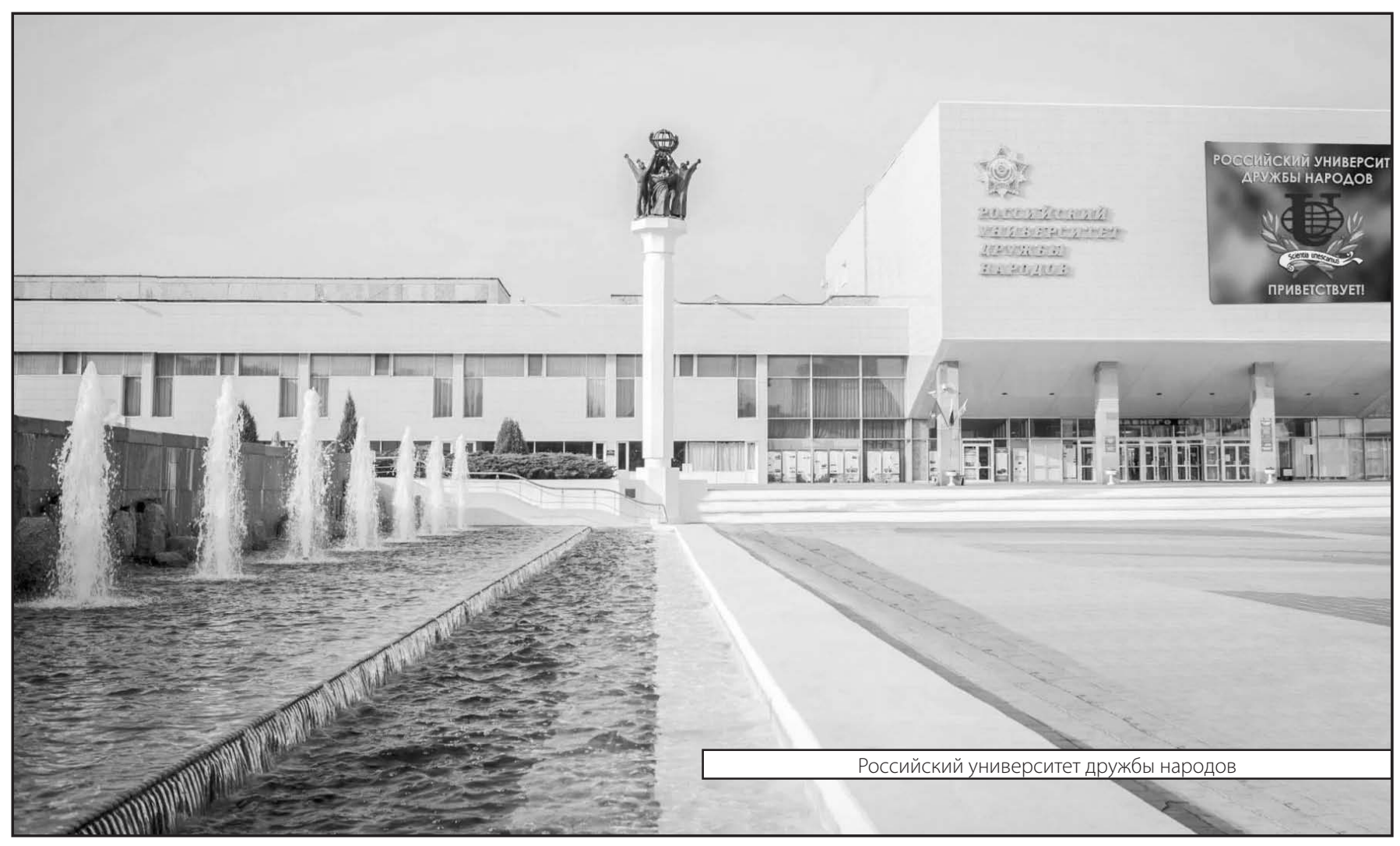

